\title{
Expatriate Performance in Overseas Assignments: The Role of Big Five Personality
}

\author{
Raduan Che Rose \\ Department of Management and Marketing, \\ Faculty of Economics and Management \\ Universiti Putra Malaysia, 43400, UPM SERDANG \\ Selangor, Malaysia \\ E-mail: rcr@econ.upm.edu.my \\ Subramaniam Sri Ramalu (Corresponding author) \\ D/A Raduan Che Rose \\ Department of Management and Marketing \\ Faculty of Economics and Management \\ Universiti Putra Malaysia, 43400, UPM SERDANG \\ Selangor, Malaysia \\ E-mail: subra@uum.edu.my \\ Jegak Uli \\ Department of Professional Development and Continuing Education \\ Faculty of Educational Studies \\ Universiti Putra Malaysia, 43400, UPM SERDANG \\ Selangor, Malaysia \\ E-mail: jegak@ace.upm.edu.my \\ Naresh Kumar \\ Department of Management and Marketing \\ Faculty of Economics and Management \\ Universiti Putra Malaysia, 43400, UPM SERDANG \\ Selangor, Malaysia \\ E-mail: naresh@econ.upm.edu.my
}

\begin{abstract}
This paper investigates the affects of Big Five personality and its dimensions on expatriate job performance. Based on sample of 332 expatriates working in Malaysia, personality factor found to be a significant determinant of expatriate job performance in international assignments. Specifically, the results of this study reveal that expatriates in Malaysia with greater conscientiousness personality fared better in their task and contextual performance. Those with greater openness to experience found to perform better in their task, contextual and assignment-specific performance. The findings of this study contributes to the body of knowledge in the cross-cultural management field and have practical implication to expatriating firms especially in the area of selection and training of candidates for international assignments.
\end{abstract}

Keywords: Personality, Job Performance, Expatriate 


\section{Introduction}

In the pace of globalization, the effectiveness of international assignment is becoming an important source of competitive advantage for many multinational organizations (Zhang \& Dodgson, 2007). Some of the strategic reasons for sending expatriates on the international assignments are to establish new international markets, spread and sustain corporate culture, facilitate subsidiary coordination and control, and transfer of technology, knowledge and skills (Huang, Chi \& Lawler, 2005; Shay \& Tracey, 2009).

Acknowledging the strategic importance of international assignments, there is serious concern among academics as well as practitioners on how best to define and eventually measure the expatriate effectiveness (Shay \& Baack, 2006). This is because the bulk of existing research tended to study expatriate cross-cultural adjustment (CCA) as the criterion of expatriate effectiveness. In fact, for many researchers CCA has been synonymous with expatriate effectiveness (Copeland \& Griggs, 1985; Mendenhall \& Oddou, 1985). Despite this development, it is still uncertain whether CCA can substitute expatriate job performance. This is because CCA does not reflect the actual role prescribed behaviors that the expatriates perform in their job, hence achieving organizational goal. According to Caligiuri (1997), approximately half of the maladjusted expatriates who remain abroad are ineffective (or performing poorly) in their foreign assignment. Additionally, not all maladjusted expatriates leave their assignments and most likely choose to complete their stay neglecting the expectations to perform in the job. In that regard, examination of expatriate job performance is valuable.

Research identifying the determinant of expatriate job performance found factors related to individual, organizational and situational are important contributing elements. In this research realm, individual differences of personality traits appear to gained considerable attention (Ones \& Viswesvaran, 1999; Caligiuri \& Day, 2000; Dalton \& Wilson, 2000; Caligiuri, 2000a; Mol, Born, Willemsen \& Van Der Molen, 2005; Shaffer, Harrison, Gregersen, Black \& Ferzandi, 2006). Personality trait believed to be a reliable predictor of workplace behaviour and job performance in the international setting similar to what has found in domestic research. The recent emergence of a unified, well-developed theory of personality, referred to as the Big Five Personality (Costa \& McCrae, 1992) particularly has provided the opportunity to test the relationship between personality and expatriate job performance.

This paper is concerned with how personality affects the job performance of expatriates assigned to Malaysia. Although a number of studies have been conducted on the relationship between personality and job performance (Dalton \& Wilson, 2000; Caligiuri, 2000a; Mol et al., 2005; Shaffer et al., 2006), it is still uncertain whether personality factor is the determinant of job performance. Moreover, in exception to Tahir and Ismail (2007), no study conducted in Malaysia. We believe that expatriate population in Malaysia is worth investigating, particularly because the country has become one of the preferred FDI destinations in the South East Asia region (MIDA, 2009). This indicates that the country will have to face a continuous increase in number of expatriates admitted to various sectors of employment. There were 35,583 approved expatriate postings in Malaysia in year 2007 alone (Malaysia, 2008). The growing trend in the number of expatriates and international assignments in Malaysia has heightened the need for research to understand how expatriates perform during their assignments in Malaysia. The purpose of this study therefore is to investigate how personality related to the job performance of expatriates assigned to Malaysia.

\section{Literature Review}

\subsection{Personality}

Personality defined as enduring emotional, interpersonal, experiential, attitudinal and motivational style that explains individual's behaviour in different situations (McCrae \& Costa, 1989). A review of the Industrial/Organizational psychology literature suggests that the sum of all personality characteristics can be categorize in five basic trait dimensions- extraversion, conscientiousness, agreeableness, openness to experience and neuroticism. These five trait dimensions subsequently labelled as the Big Five Personality (Hough, 1992; Digman, 1997).

The first dimension, extraversion, has been related with heightened level of sociability. Individuals high in extraversion tend to like groups and gatherings, to be talkative and energetic and generally to be more active and assertive (Costa \& McCrae, 1992). An extravert person considered sociable and outgoing with others (Huang et al., 2005). Conscientiousness dimension described as a form of conformity to rules and standards, and linked to traits like responsibility, organization, hard work, impulse control and prudence (Barrick \& Mount, 1991; Hogan \& Ones, 1997). Individuals high on conscientiousness is also dependable and trustworthy (Costa \& McCrae, 1992). The third dimension, agreeableness has been associated with conformity with others and friendliness in the interpersonal setting (Hogan \& Hogan, 1986; Digman, 1990). Individuals high on agreeableness tend to be 
more helpful and sympathetic towards others, as well as more trusting of the intentions of other people (Costa \& McCrae, 1992). According to Laursen, Pulkkinen and Adams (2002), agreeableness trait related to higher levels of social compliance and self-control, and lower levels of aggression. The fourth dimension, openness to experience appears to be a personality trait that reflects individuals' habitual willingness to try new ideas, tolerate ambiguity and dissonance and generally be curious and eager to learn (Barrick \& Mount, 1991). Individuals high on openness to experience tend to be open minded, original in thought, intelligent, imaginative, and non-judgmental. Finally, neuroticism personality is associated with lessened emotional control and stability (Mount \& Barrick, 1995). Neurotic individuals tend to have relatively negative core self-evaluations, leading to emotional distress and associated behaviours (Rusting \& Larsen, 1998). Neuroticism also related to a person's general tendency to experience negative effects such as fear, sadness, embarrassment, anger, guilt, and disgust (Dalton \& Wilson, 2000).

Albeit limited, the available studies have linked personality factor with various expatriate outcomes such as adjustment (Shaffer et al., 2006), job performance (Mol et al., 2005) and premature return (e.g., Caligiuri, 2000a).

\subsection{Job Performance}

Theoretically, individual job performance is a function of knowledge, skills, abilities, and motivation directed at role prescribed behavior, such as formal job responsibilities (Campbell, 1999). Behavior or actions that are relevant to an organization's goals accomplishment considered as individual job performance (Campbell, McCloy, Oppler, \& Sager, 1993). Theory of job performance has indicated that job performance is a multidimensional construct consist of task dimension (often production or deadline driven and sometimes referred to as "in-role") and contextual dimension (sometimes considered discretionary and often termed "extra-role") (Borman \& Motowidlo, 1993). This theory applies equally well in international setting (Caligiuri, 1997). In the expatriate management, international assignees not only expected to perform in their task and contextual performance dimensions but also to accomplish certain assignment specific tasks (e.g., transferring knowledge and technology). This third dimension labeled as assignment specific performance (Caligiuri, 1997; Caligiuri \& Day, 2000).

A review of literature indicates individual differences such as personality trait, self-efficacy, motivation, communicational ability, stress tolerance, relational ability, and prior international experience related to expatriate job performance (e.g., Parker \& McEvoy, 1993; Ones \& Viswesvaran, 1999; Shaffer, Harrison, \& Gilley, 1999; Caligiuri, 2000a; Hechanova, Beehr, \& Christiansen, 2003; Holopainen \& Björkman, 2005; Shaffer et al., 2006).

\subsection{Hypotheses Development}

Major studies that have dealt with the relationship between personality and job performance include, but are not limited to those of Sinangil and Ones (1998), Ones and Viswesvaran (1999), Dalton \& Wilson (2000), Caligiuri (2000a), Mol et al. (2005) and Shaffer et al. (2006). Unfortunately, these results show a mixed finding on the relationship between dimensions of the Big Five personality and job performance. For instance, while Ones and Viswesvaran (1999) found conscientiousness was perceived to be the most important personality trait for expatriate job performance, Sinangil and Ones (1998), on the other hand, found that dependability (conscientiousness) is a poor predictor of expatriate job performance. In a recent study, Mol et al. (2005) found that there is no support for the relationship between openness to experience and expatriate job performance whereas many researchers have hypothesized it to be predictive for this criterion (e.g., Ones \& Viswesvaran, 1997; Shaffer et al., 2006).

Despite this findings, others have argued that high performing international assignees tend to share certain personality traits (e.g., Black, 1990; Caligiuri, 2000a; Dalton \&Wilson, 2000; Mol et al., 2005; Shaffer et al., 2006). A meta-analysis conducted by Mol et al. (2005) found that extraversion, emotional stability, agreeableness, and conscientiousness were reliable predictor of expatriate performance. Hence, for this reason researchers like Borman, White, Pulakos and Oppler (1991) support the importance of using personality above and beyond ability in prediction of performance in the international setting.

Drawing from the evolutionary personality psychology theory (Buss, 1991), the Big Five personality characteristics has been linked with universal adaptive mechanisms that allow individuals to adapt with and meet the demands of physical, social and cultural environments. These adaptive mechanisms include humans' ability to learn hierarchies in society (Extroversion), "their willingness to cooperate (Agreeableness), their capacity for reliable work and enduring commitment (Conscientiousness), their ability to handle stress (Emotional Stability), 
and their propensity for innovation or astuteness in solving problems (Openness, Intellect)" (Buss, 1991, cited in Caligiuri, 2000a, p.71).

Likewise, from a socioanalytic perspective, Hogan (1996) suggests that people have evolved in their ability to portray an image (or reputation) consistent with the society's view of success, to ultimately achieve status and acceptance. Possessing certain personality characteristics will affect how well an individual perceived to be suited for a given role (Hogan, 1996). Hence, individuals who possess the appropriate personality trait for a given role in a given environment will perform better in their job compared with who do not possess the appropriate personality characteristics for that same role (Caligiuri, 2000a). Broadly, it can be conclude that the Big Five personality is a valid predictor of expatriate job performance. In order to establish the relationship between personality and job performance, we have decided to test the presumed relationship as follows:

$\mathrm{H} 1$ : There is a positive relationship between personality and job performance.

Specifically, (H1a) extraversion, (H1b) agreeableness, (H1c) conscientiousness, (H1d) openness to experience, and (H1e) emotional stability will relate positively to (i) task performance, (ii) contextual performance and (iii) assignment-specific performance.

\section{Methodology}

\subsection{Sample}

The participants in the study were expatriates currently working and residing in Malaysia. A total of 500 mail and 500 online questionnaires were distributed. Of these, 339 questionnaires replied. The initial response rate was $34 \%$, which is consistent with other typical response rates $(20-30 \%)$ in most expatriate studies (e.g., Harrison \& Shaffer, 2005). Out of 339, 7 were unusable responses, resulting in final sample of 332, representing a 33\% return rate. The sample included $252(75.9 \%)$ men and $80(24.1 \%)$ women. Participants age included 122 (36.7\%) between $42-52$ and $103(31.0 \%)$ between 31-41 years old. Participants marital status included 251 $(75.6 \%)$ married and $54(16.3 \%)$ unmarried. In terms of prior overseas experience, 251 (75.6) has previous international experience and $81(24.4 \%)$ has no experience. Participants job status included $169(50.9 \%)$ in managerial position and $163(49.1 \%)$ in non-managerial position. Participants education status included 119 $(35.8 \%)$ with degree and $85(25.6 \%)$ with masters degree. Distribution of sample by industry sector included 112 $(33.7 \%)$ working in service sector, $109(32.8 \%)$ in other sector and $84(25.3 \%)$ in manufacturing. Participants length of stay in Malaysia ranged from 2 to 24 years $(M=4.80, S D=3.40)$. Tenure with present organization ranged from 2 to 25 years $(M=7.25, S D=4.45)$. The participants are come from various countries with majority $51(15.4 \%)$ are from India, 39 (11.7\%) from UK, 32 (9.6\%) from Australia, and 200 (63.3\%) from some other 42 countries.

\subsection{Instrumentation}

Four background variables (gender, prior overseas experience, length of stay in Malaysia and language proficiency) identified as correlates of expatriate attitudes and behaviors controlled for in this study (Hechanova et al., 2003; Shaffer \& Harrison, 1998). This is to avoid our findings from be spuriously attributed to various background characteristics.

The main predictor, personality measured with the 44-item, self-reported Big Five Inventory (BFI) adopted from John and Srivastava (1999). The scale includes eight items for extraversion, nine for agreeableness, nine for conscientiousness, eight for neuroticism and ten for openness to experience personality dimension. Sample item include "I see myself as someone who has an assertive personality" for extraversion; "I see myself as someone who is helpful and unselfish with others" for agreeableness; "I see myself as someone who is a reliable worker" for conscientiousness; "I see myself as someone who can be moody" for neuroticism; and "I see myself as someone who is original, comes up with new ideas" for openness to experience. Respondents were asked to use a seven-point Likert-type scale range from strongly disagree (1) to strongly agree (7) to indicate the extent to which each item describes their characteristic. Cronbach's alpha for this scale was 0.83 (John \& Srivastava, 1999).

Seventeen items measured the criterion variable, job performance. Of these, five items were adapted from work of Black and Porter (1991) and twelve items from work of Caligiuri (1997). The scale includes five items for task performance, five for contextual performance, and seven for assignment-specific performance. Sample item include "your effectiveness at completing tasks on time" for task performance; "your effectiveness at foster organizational commitment among host country nationals" for contextual performance; and "your effectiveness at transferring information across strategic units" for assignment-specific performance. Respondents were asked to rate their perceived ability in each of the job performance items in comparison to their peers in similar 
positions on seven-point Likert-type scale ranging from 1 (much worse than most) to 7 (much better than most) for each items. Cronbach's alpha for task, contextual and assignment-specific performance was $0.86,0.63$, and 0.67 respectively (Caligiuri, 1997; Shay \& Baack, 2006).

\section{Results}

Table 1 presents the means, standard deviations, reliability coefficients, and bivariate correlations among the study variables. Personality was positively related to job performance $(r=0.28, p<0.05)$. Correlations between dimensions of personality and dimensions of job performance reveal that agreeableness personality was correlated positively with task, contextual and assignment-specific performance ( $r$ ranges from 0.11 to 0.20 , all $p$ s <0.05). Extraversion personality correlated positively with contextual $(r=0.19, \quad \mathrm{p}<0.05)$ and assignment-specific performance $(r=0.13, \mathrm{p}<0.05)$. Conscientiousness personality was correlated positively with task, contextual and assignment-specific performance ( $r$ ranges from 0.21 to 0.27 , all $p \mathrm{~s}<0.05$ ). Openness to experience personality was correlated positively with task, contextual and assignment-specific performance $(r$ ranges from 0.17 to 0.22 , all $p$ s $<0.05$ ). Emotional stability was correlated positively with task, contextual and assignment-specific performance ( $r$ ranges from 0.11 to 0.20 , all $p$ s $<0.05$ ) (opposite pole of neuroticism personality).

$\mathrm{H} 1$ predicted that there is a positive relationship between personality and job performance. A hierarchical regression conducted to test the hypothesis. The results of the first step of the regression analysis for this hypothesis are in Table 2. When the control variables were entered in the first step, the regression model was statistically significant, $R^{2}=.055$, Adjusted $R^{2}=.043, F(4,327)=4.724, p<0.05$. Gender $(\beta=.194)$ and length of stay in Malaysia $(\beta=.123)$ both $p$ s $<0.05$ were positively associated with job performance.

When personality was added to the model in Step 2, the full model was statistically significant, $R^{2}=.149$, Adjusted $R^{2}=.136, F(5,326)=11.457, p<0.05$. Again, gender $(\beta=.222)$ and length of stay in Malaysia $(\beta$ $=.137$ ) both $p \mathrm{~s}<0.05$ were positively associated with job performance, indicating that male expatriates and who had been in Malaysia for a longer period of time tended to have better job performance. Personality was statistically significant $(\beta=.317, p<0.05)$. This indicates that individuals with higher levels of personality tended to have better job performance. This finding supports hypothesis H1. The change in $\mathrm{R}^{2}$ between Step 1 and Step 2 was significant $\left(\Delta \mathrm{R}^{2}=.095, p<0.05\right)$ indicating that personality explains an additional $9.5 \%$ of the variance in job performance, even when the effects of the control variables are statistically controlled.

The test the sub-hypotheses 1 it requires an examination on the relationship between dimensions of personality and dimensions of job performance. Again, a hierarchical regression analysis conducted (See Table 3). Conscientiousness personality was significantly related to task $(\beta=.210)$ and assignment-specific performance $(\beta=.131)$ both $p \mathrm{~s}<0.05$ indicating that higher the conscientiousness personality, higher the task and assignment-specific performance will be. Openness to experience was associated significantly with all three dimensions of job performance, task $(\beta=.174)$, contextual $(\beta=.135)$ and assignment specific performance $(\beta$ $=.120)$ all $p \mathrm{~s}<0.05$, indicating that those higher in openness to experience personality tended to have higher level of task, contextual and assignment specific performance. The findings of this study supported hypothesis H1c(i), H1c(ii), H1d(i), H1d(ii), and H1d(iii).

The change in $\mathrm{R}^{2}$ between Step 1 and Step 2 was significant for all three dimensions of job performance, task $\left(\Delta \mathrm{R}^{2}=.090\right)$, contextual $\left(\Delta \mathrm{R}^{2}=.086\right)$ and assignment specific performance $\left(\Delta \mathrm{R}^{2}=.078\right)$ all $p \mathrm{~s}<0.05$. This indicates that agreeableness, extraversion, conscientiousness, neuroticism and openness personality traits together explain an additional $9.00,8.6$ and $7.8 \%$ of the variance in task, contextual and assignment specific performance respectively, even when the effects of the control variables statistically controlled.

\section{Discussion and Conclusion}

The purpose of this paper is to enhance our knowledge of the individual determinant of job performance for expatriates assigned to Malaysia. Specifically, this study explored the affects of personality trait on job performance. The results indicated that after accounting for control variables of gender, prior overseas experience, duration of stay in the host country and language fluency, personality trait significantly related to job performance. In this study, greater task performance among expatriates is associated with greater conscientiousness and openness to experience. Greater contextual performance related to being greater in openness to experience while greater assignment-specific performance related to greater conscientiousness and openness to experience. Openness to experience is the only personality trait that significantly related to all three dimensions of expatriate job performance, task, contextual and assignment-specific performance. In general, the findings of the present study are consistent with results of prior studies (e.g., Ones \& Viswesvaran, 1999; Caligiuri \& Day, 2000; Dalton \& Wilson, 2000; Caligiuri, 2000a; Mol et al., 2005; Shaffer et al., 2006). The 
insignificant affects of other dimensions of personality trait on expatriate job performance are somewhat disappointing.

The significant positive relationship found between conscientiousness and job performance is as expected. Specifically, conscientiousness personality positively related to task and assignment-specific performance in this study. This implies that the greater the conscientiousness personality, greater the task and assignment-specific performance will be. The results of this study appear to be consistent with the findings of Ones and Viswesvaran (1999) who identified conscientiousness as the strongest of the Big Five Personality traits in its perceived influence on expatriate's job performance. Qualities associated with conscientiousness personality especially conforming to rules and standards and traits like responsibility, organization, hard work, impulse control and prudence (Barrick \& Mount, 1991; Hogan \& Ones, 1997) seem to be relevant in accomplishing task-oriented requirements of task and assignment-specific performance.

As expected, openness to experience positively related to expatriate job performance. In this study, openness to experience significantly related to task, contextual and assignment-specific performance. This indicates that the greater the openness to experience, greater the task, contextual and assignment-specific performance will be. Traits such as original in thought, innovative, willing to take risks and flexible among individuals high on openness to experience (Costa \& McCrae, 1992; Ones \& Viswesvaran, 1997) allow them to form accurate expectations about their new tasks in the international assignments. This in turn will facilitate individuals to meet the performance standard and expectation in both the technical (i.e., task performance) and non-technical (i.e., contextual and assignment-specific) aspects of job performance.

The lack of support for the affects of agreeableness and extraversion personality on expatriate job performance in this study is quite disappointing. This is because the qualities associated with agreeableness and extraversion personality generally facilitate expatriates to have effective communication and relationship with host country nationals and other expatriates (Mendenhall \& Oddou, 1985; Shaffer et al., 2006) hence it is expected to be associated at least with non-technical aspects of job performance such as contextual and assignment-specific performance. The tendency to spend more time on getting along with others (i.e., agreeable) and being active in building a social network (i.e., extravert) with host country nationals and other expatriates in the host country may inhibit individuals from focusing on meeting their core expectations of their job, hence job performance suffers.

Given these results, there are few implications for organizations and individuals considering international assignments. The significant positive relationship between personality and job performance suggest that personality is important stable intercultural competency in enhancing expatriate job performance (Leiba-O'Sullivan, 1999). Expatriating firms can consider the use of selection methods that include testing for personality especially the conscientiousness and openness to experience personality trait in finding prospective expatriates for international assignments. However, it is necessary to consider personality traits in relation to host country culture. The findings of this study has provided initial evidence that individuals high on openness to experience and conscientiousness will perform in their job when assigned to host culture predominantly collective in nature such as Malaysia (Hofstede, 1991). In that regard, the findings of this study may be generalized to expatriates working in some other southeast Asian nations. In addition to selection, cross-cultural training is also an available HR intervention to improve the likelihood of expatriate job performance. MNCs should think of selection based on personality as the precursor to cross-cultural training. That is, MNCs should identify those expatriate candidates with the requisite personality characteristics, and then offer cross-cultural training to those identified. Cross-cultural training may only be effective when the expatriates are predisposed to success in the first place.

This study has certain limitations that provide venues for future research. First, job performance is not the only criterion for expatriate effectiveness. Other criterion such as job satisfaction, organizational commitment, and turnover intention should be included in the future study. Second, we acknowledge that some concerns might exist in that self-reported measures have social desirability and common method bias problem. Therefore, future research should include assessment from multiple sources including peers, subordinates, and superiors. Third, a cross-sectional study design restricts the ability to prove a cause-effect relationship. Future research should consider longitudinal study if replication of this study is to establish the predictive functions of personality trait over time and space. Third, this study did not consider the possible moderating effects of the contextual factors on the predictor-outcome relationships. Potential moderators such as cultural distance (i.e. home vs. host country), assignment type (e.g., managerial vs. non-managerial), assignment tenure and prior overseas experience may help to further enhance our understanding on the phenomenon under investigation. 


\section{References}

Barrick, M.R., \& Mount, M.K. (1991). The Big Five personality dimensions and job performance. Personnel Psychology, 41, 1-26.

Black, J.S. (1990). The relationship of personal characteristics with the adjustment of Japanese expatriate managers. Management International Review, 30,119-134.

Black, J.S., \& Porter, L.W. (1991). Managerial behavior and job performance: A successful manager in Los Angeles may not be successful in Hong Kong. Journal of International Business Studies, 22 (1), 99-114.

Borman, W. C., White, L. A., Pulakos, E. D., \& Oppler, S. H. (1991). Models of supervisory job performance ratings. Journal of Applied Psychology, 76, 863-872.

Borman, W.C., \& Motowidlo, S.J. (1993). Expanding the criterion domain to include elements of contextual performance. In N. Schmitt \& W. C. Borman (Eds.), Personnel selection in organizations (pp. 71-98). San Francisco: Jossey-Bass.

Buss, D.M. (1991). Evolutionary personality psychology. In M.R. Rosenzweig \& L.W. Porter (Eds.), Annual Review of Psychology, Vol. 42, pp.459-492. Palo Alto, CA: Annual Reviews Inc.

Caligiuri P.M. (1997). Assessing expatriate success: Beyond just "being there.” In Saunders DM, Aycan Z (Eds.), New approaches to employee management (Vol. 4, pp. 117-140). Greenwich, CT: JAI Press.

Caligiuri, P.M. (2000a). The Big Five personality characteristics as predictors of expatriate's desire to terminate the assignment and supervisor-rated performance. Personnel Psychology, 53, 67-88.

Caligiuri, P.M., \& Day, D.V. (2000). Effects of Self-Monitoring on Technical, Contextual, and Assignment-Specific Performance. Group \& Organization Management, 25(2), 154-174.

Campbell, J.P. (1999). The definition and measurement of performance in the new age. In D. R. Ilgen \& E. D. Pulakos (Eds.), The changing nature of performance: Implications for staffing, motivation, and development: 399-429. San Francisco, Calif: Jossey-Bass.

Campbell, J.P., McCloy, R.A., Oppler, S.H., \& Sager, C.E. (1993). A theory of performance. In E. Schmitt, W. C. Borman, \& Associates (Eds.), Personnel selection in organizations (pp. 35-70). San Francisco: Jossey-Bass.

Copeland, L., \& Griggs, L. (1985). Going International. Random House, New York, NY.

Costa, P.T., Jr., \& McCrae, R.R. (1992). Revised NEO Personality Inventory and NEO Five Factor Inventory: Professional Manual. Odessa, FL: PAR.

Dalton, M., \& Wilson, M. (2000). The relationship of the five-factor model of personality to job performance for a group of Middle Eastern expatriate managers. Journal of Cross-Cultural Psychology, 31, 250-258.

Digman, J.M. (1990). Personality structure: Emergence of the five-factor model. In M. R. Rosenzweig\& L.W. Porter (Eds.), Annual review of psychology (Vol. 41, pp. 417-440). Palo Alto, CA: Annual Reviews.

Digman, J.M. (1997). Higher-order factors of the big five. Journal of Personality and Social Psychology, 73, 1246-1256.

Hechanova, R., Beehr, T.A., \& Christiansen, N.D. (2003). Antecedents and consequences of employees' adjustment to overseas assignments: A meta-analytic review. Applied Psychology, 52, 213-236.

Hofstede, G. (1991). Cultures and organizations: Software of the mind. London: McGraw-Hill.

Hogan R. (1996). A socioanalytic perspective on the five-factor model. In Wiggins J.S. (Ed.). The five-factor model of personality: Theoretical perspectives, pp. 163-179, New York: Guilford.

Hogan, J., \& Hogan, R. (1986). Hogan Personnel Selection Series Manual. Tulsa, OK: Hogan Assessment Systems.

Hogan, J., \& Ones, D.S. (1997). Conscientiousness and integrity at work. In R. Hogan, J. A. Johnson, \& S. R. Briggs (Eds.), Handbook of personality psychology (pp. 849-870). New York: Academic Press.

Holopainen, J., \& Björkman, I. (2005). The personal characteristics of the successful expatriate: A critical review of the literature and an empirical investigation. Personnel Review, 34 (1), 37-50.

Hough, L.M. (1992). The "Big Five" personality variables-construct confusion: Description versus prediction. Human Performance, 5, 139-156. 
Huang, T.J., Chi, S.C., \& Lawler, J.J. (2005). The relationship between expatriate's personality traits and their adjustment to international assignments. International Journal of Human Resource Management, 16, 1656-1670.

Immigration Department of Malaysia. (2008). Expatriate Statistical Report Dated from 01/01/2007 to 31/12/2007. Employment Pass Section, Immigration Department, Malaysia.

John, O.P., \& Srivastava, S. (1999). The Big Five trait taxonomy: History, measurement, and theoretical perspective. In L. A. Pervin \& O. P. John (Eds.), Handbook of personality: Theory and research (2nd ed., pp. 102-138). New York: Guilford.

Laursen, B., Pulkkinen, L., \& Adams, R. (2002). The antecedents and correlates of agreeableness in adulthood. Developmental Psychology, 38, 591-603.

Leiba-O'Sullivan, S. (1999). The distinction between stable and dynamic cross-cultural competencies: implications for expatriate trainability. Journal of International Business Studies, 30(4), 709-725.

Malaysian Industrial Development Authority. (2009). Industry leaders: Malaysia offers significant cost advantage for regional establishments. [Online] Available: http://www.mida.gov.my (October 6, 2009).

McCrae, R.R., \& Costa, P.T., Jr. (1989). Reinterpreting the Myers-Briggs Type Indicator from the perspective of the five-factor model of personality. Journal of Personality, 57, 17-40.

Mendenhall, M. \& Oddou G. (1985). The Dimensions of Expatriate Acculturation: A Review. Academy of Management Review, 10, 39-47.

Mol, S.T., Born, M.P., Willemsen, M.E., \& Van Der Molen, H.T. (2005). Predicting expatriate job performance for selection purposes: A quantitative review. Journal of Cross-Cultural Psychology, 36(5), 590-620.

Mount, M.K., \& Barrick, M.R. (1995). The Big Five personality dimensions: Implications for research and practice in human resources management. In K. M. Rowland \& G. Ferris (Eds.), Research in personnel and human resources management (Vol. 13, pp. 153-200). Greenwich, CT: JAI Press.

Ones, D., \& Viswesvaran, C. (1999). Relative importance of personality dimensions for expatriate selection: a policy capturing study. Human Performance, 12(3), 275-290.

Parker, B., \& McEvoy, G.M. (1993). Initial Examination of a Model of Intercultural Adjustment. International Journal of Intercultural Relations, 17, 355-379.

Rusting, C.L., \& Larsen, R.J. (1998). Personality and cognitive processing of affective information. Personality and Social Psychology Bulletin, 24, 200-213.

Shaffer, M.A., \& Harrison, D.A. (1998). Expatriates' psychological withdrawal from international assignments: Work, nonwork, and family influences. Personnel Psychology, 51, 87-118.

Shaffer, M.A., Harrison, D.A., \& Gilley, K.M. (1999). Dimensions, determinants, and differences in the expatriate adjustment process. Journal of International Business Studies, 30, 557-581.

Shaffer, M.A., Harrison, D.A., Gregersen, H., Black, J.S., \& Ferzandi, L.A. (2006). You can take it with you: Individual differences and expatriate effectiveness. Journal of Applied Psychology, 91, 109-125.

Shay, J.P., \& Baack, S. (2006). An empirical investigation of the relationships between modes and degree of expatriate adjustment and multiple measures of performance. International Journal of Cross Cultural Management, 6 (3), 275-294.

Shay, J.P., \& Tracey, J.B. (2009). Expatriate adjustment and effectiveness: The mediating role of managerial effectiveness. Journal of International Management, 15, 401-412.

Sinangil, H.K., \& Ones, D.S. (1998). Personality Correlates of Expatriate Adjustment in Turkey. Paper presented at the International Congress of Applied Psychology, San Francisco.

Tahir, A.H.M., \& Ismail, M. (2007). Cross-cultural Challenges and Adjustment of Expatriates: A Case Study in Malaysia. Turkish Journal of International Relations, 6 (3\&4), 72-99.

Zhang, M.Y., \& Dodgson, M. (2007). A roasted duck can still fly away: A case study of technology, nationality, culture and the rapid and early internationalization of the firm. Journal of World Business, 42,336-349. 
Table 1. Descriptive statistics, reliability coefficients and correlations $(\mathrm{N}=332)$

\begin{tabular}{|c|c|c|c|c|c|c|c|c|c|c|c|c|c|c|c|c|}
\hline Variable & Mean & SD & 1 & 2 & 3 & 4 & 5 & 6 & 7 & 8 & 9 & 10 & 11 & 12 & 13 & 14 \\
\hline 1. Gender & 0.76 & 0.43 & . & & & & & & & & & & & & & \\
\hline 2. Prior experience & 0.76 & 0.43 & $0.12^{*}$ & - & & & & & & & & & & & & \\
\hline 3. Length of stay & 4.80 & 3.40 & 0.03 & -0.03 & - & & & & & & & & & & & \\
\hline 4. Language & 3.57 & 0.70 & $-0.16^{* *}$ & $0.21^{* *}$ & $0.16^{* *}$ & - & & & & & & & & & & \\
\hline 5. Personality & 4.92 & 0.33 & -0.08 & $0.20^{* *}$ & -0.04 & $0.11^{*}$ & $(0.71)$ & & & & & & & & & \\
\hline 6. Performance & 5.58 & 0.56 & $0.19^{* *}$ & 0.01 & $0.14^{*}$ & 0.04 & $0.28 * *$ & $(0.91)$ & & & & & & & & \\
\hline 7. Agreeableness & 5.48 & 0.69 & 0.32 & $0.15^{* *}$ & -0.02 & 0.09 & $0.62^{* *}$ & $0.19^{* *}$ & $(0.74)$ & & & & & & & \\
\hline 8. Extraversion & 4.91 & 0.81 & .0 .09 & $0.19^{* *}$ & -0.07 & $0.16^{* *}$ & $0.62^{* *}$ & $0.16^{* *}$ & $0.26 * *$ & $(0.76)$ & & & & & & \\
\hline 9. Conscientiousness & 5.46 & 0.73 & 0.08 & $0.14^{*}$ & 0.01 & .0 .06 & $0.69^{* *}$ & $0.28^{* *}$ & $0.44^{* *}$ & $0.34^{* *}$ & $(0.77)$ & & & & & \\
\hline 10. Openness & 5.36 & 0.56 & -0.05 & $0.16^{* *}$ & -0.02 & $0.18^{* *}$ & $0.67^{* *}$ & $0.24^{* *}$ & $0.20^{* *}$ & $0.30^{* *}$ & $0.35^{* *}$ & $(0.73)$ & & & & \\
\hline 11. Neuroticism & 3.16 & 0.82 & $-0.15^{* *}$ & $-0.17^{* *}$ & -0.00 & .0 .09 & $-0.22^{* *}$ & $-0.19^{* *}$ & $-0.44^{* *}$ & $-0.44^{* *}$ & $-0.50^{* *}$ & $-0.18^{* *}$ & $(0.76)$ & & & \\
\hline 12. TP & 5.80 & 0.72 & $0.16^{* *}$ & 0.03 & $0.12^{*}$ & -0.02 & $0.21^{* *}$ & $0.77^{* *}$ & $0.11^{*}$ & 0.06 & $0.27^{* *}$ & $0.22 * *$ & $-0.14^{* *}$ & $(0.87)$ & & \\
\hline 13. CP & 5.50 & 0.62 & $0.12^{*}$ & 0.03 & $0.17^{* *}$ & $0.11^{*}$ & $0.25 * *$ & $0.89^{* *}$ & $0.20^{* *}$ & $0.19^{* *}$ & $0.21^{* *}$ & $0.21^{* *}$ & $-0.20^{* *}$ & $0.49^{* *}$ & $(0.81)$ & \\
\hline 14. SP & 5.44 & 0.67 & $0.21^{* *}$ & .0 .04 & 0.03 & -0.03 & $0.24^{* *}$ & $0.83^{* *}$ & $0.17^{* *}$ & $0.13^{*}$ & $0.22^{* *}$ & $0.17^{* *}$ & $-0.11^{*}$ & $0.47^{* *}$ & $0.65 * *$ & $(0.85)$ \\
\hline
\end{tabular}

Notes: ${ }^{*} p<05 . \quad \quad{ }^{* *} p<01 \quad \mathrm{TP}=$ task performance; $\mathrm{CP}=$ contextual performance; $S \mathrm{P}=$ specific performance

Coefficient alphas are presented along the diagonal

Table 2. Results of the Hierarchical Regression Analysis with Personality as a Predictor of Job Performance (N=332)

\begin{tabular}{lllllll}
\hline & \multicolumn{3}{c}{ Step 1 } & \multicolumn{3}{c}{ Step 2 } \\
Variable & $\beta$ & $t^{2} p$ & $\beta$ & $t$ & $p$ \\
\hline Gender & .194 & 3.502 & .001 & .222 & 4.208 & .000 \\
Prior overseas experience & -.020 & -.350 & .727 & -.080 & -1.485 & .138 \\
Length in Malaysia & .123 & 2.251 & .025 & .137 & 2.642 & .009 \\
Language proficiency & .054 & .954 & .341 & .034 & .621 & .535 \\
Personality & - & - & - & .317 & 6.029 & .000 \\
\hline
\end{tabular}

Note: Gender and prior experience are dummy-coded categorical variables.

Step $1 R^{2}=.055$, Adjusted $R^{2}=.043, F(4,327)=4.724, p=.001 ;$ Step $2 R^{2}=.149$, Adjusted $R^{2}=.136, F(5,326)=11.457, p=.000, \Delta \mathrm{R}^{2}=.095, p=.000$. 
Table 3. Results of the Hierarchical Regression Analysis between Dimensions of Personality and Dimensions of Job Performance $(\mathrm{N}=332)$

\begin{tabular}{|c|c|c|c|c|c|c|}
\hline \multirow[t]{3}{*}{ Variable } & \multicolumn{2}{|c|}{ Task } & \multicolumn{2}{|c|}{ Contextual } & \multicolumn{2}{|c|}{ Specific } \\
\hline & Step 1 & Step 2 & Step 1 & Step 2 & Step 1 & Step 2 \\
\hline & $\beta(t)$ & $\beta(t)$ & $\beta(t)$ & $\beta(t)$ & $\beta(t)$ & $\beta(t)$ \\
\hline Gender & $.150(2.693)^{* *}$ & $.144(2.629)^{* *}$ & $.132(2.375)^{*}$ & $.135(2.474)^{*}$ & $.216(3.898)^{* * *}$ & $.234(4.252)^{* * *}$ \\
\hline Prior experience & $.018(.313)$ & $-.033(-.588)$ & $-.004(-.074)$ & $-.070(-1.268)$ & $-.070(-1.258)$ & $-.128(-2.314)^{*}$ \\
\hline Length of stay & $.118(2.133)^{*}$ & $.116(2.177)^{*}$ & $.146(2.677)^{* *}$ & $.161(3.047)^{* *}$ & $.025(.451)$ & $.036(.680)$ \\
\hline Language & $-.015(-.260)$ & $-.019(-.340)$ & $.113(1.976)^{*}$ & $.076(1.338)$ & $.017(.290)$ & $-.004(-.064)$ \\
\hline Agreeableness & & $-.010(-.156)$ & & $.094(1.553)$ & & $.112(1.840)$ \\
\hline Extraversion & & $-.034(-.559)$ & & $.102(1.665)$ & & $.100(1.626)$ \\
\hline Conscientiousness & & $.210(3.139)^{* *}$ & & $.073(1.103)$ & & $.131(1.958)^{*}$ \\
\hline Neuroticism & & $-.013(-.194)$ & & $-.040(-.603)$ & & $.082(1.214)$ \\
\hline Openness & & $.174(2.989)^{* *}$ & & $.135(2.334)^{*}$ & & $.120(2.069)^{*}$ \\
\hline $\mathrm{R}^{2}$ & .038 & .129 & .052 & .138 & .048 & .126 \\
\hline $\operatorname{Adjt} R^{2}$ & .027 & .104 & .041 & .114 & .036 & .102 \\
\hline$\Delta \mathrm{R}^{2}$ & & $.090 * * *$ & & $.086^{* * *}$ & & $.078 * * *$ \\
\hline \multirow[t]{2}{*}{$\mathrm{F}$} & $(4,327)$ & $(9,322)$ & $(4,327)$ & $(9,322)$ & $(4,327)$ & $(9,322)$ \\
\hline & $3.268^{*}$ & $5.290 * * *$ & $4.528 * *$ & $5.736 * * *$ & $4.104 * *$ & $5.167 * * *$ \\
\hline
\end{tabular}

Note: $\quad * p<.05 . \quad * * p<.01 \quad * * * p<.001$

Note: Gender and prior experience are dummy-coded categorical variables 